\title{
ОСОБЕННОСТИ ОРГАНИЗАЦИИ ДЕЯТЕЛЬНОСТИ ОРГАНОВ ВНУТРЕННИХ ДЕЛ ПО ВЫЯВЛЕНИЮ ПРИЗНАКОВ ЭКСТРЕМИСТСКОЙ ДЕЯТЕЛЬНОСТИ
}

\section{SOME ISSUES OF ORGANIZING THE ACTIVITIES OF LAW ENFORCEMENT AGENCIES TO IDENTIFY SIGNS OF EXTREMIST ACTIVITY}

\section{A. Antoshchenko}

Summary. The article is devoted to an important area of law enforcement activity as a counteraction to extremist manifestations.

The author focuses on the fact that in the fight against the considered negative phenomenon, the most important task is to identify signs of extremist manifestations, namely, obtaining initial information. Since this will allow you to take timely preventive measures that will minimize the consequences of this type of illegal activity.

The author analyzes approaches to obtaining initial information in the activities of law enforcement agencies. Based on this analysis, practical recommendations are given, taking into account problematic issues in the organization of law enforcement agencies in the fight against this type of offense.

In the course of the research, we used a formal logical method, a systematic analysis of the norms of Russian legislation, and comparative law.

Keywords: extremism, signs of extremist activity, offense, law enforcement agencies.

\author{
Антощенко Алексей Владимирович \\ Дочент, Владивостокский филиал ФГКОУ ВО \\ «Дальневосточный юридический институт МВД \\ Poccuu» \\ Kotova-vg@rambler.ru
}

Аннотация. Статья посвящена важному направлению деятельности правоохранительных органов - противодействие экстремистским проявлениям.

Автор акцентирует внимание на том, что в борьбе с рассматриваемым негативным явлением важнейшей задачей является выявление признаков экстремистских проявлений, а именно получение первоначальной информации. Так как это позволит своевременно принять превентивные меры, которые позволят минимизировать последствия данного вида противоправной деятельности.

Автором проведен анализ подходов в деятельности правоохранительных органов к получению первоначальной информации. На основе этого анализа даны практические рекомендации, с учетом проблемных вопросов в организации деятельности правоохранительных органов в борьбе с рассматриваемым видом правонарушений.

В ходе проведения исследования использовался формально-логический метод, системный анализ норм российского законодательства, сравнительное правоведение.

Ключевые слова: экстремизм, признаки экстремистской деятельности, правонарушение, правоохранительные органы.

начинаются с выявления признаков экстремистской деятельности, т.е. информации о лицах, от которых можно ожидать таких действий, а также о фактах их преступной деятельности.

Выявление лиц, имеющих намерение совершить преступление экстремистской направленности, предполагает получение сведений прежде неизвестных правоохранительным органам и имеющих значение для решения задач оперативно-розыскной деятельности, нуждающихся в проверке. Данные сведения в теории оперативно-розыскной деятельности именуются как «первичная оперативно-розыскная информация», а их выявление ассоциируется с одной из основных форм оперативно-розыскной деятельности, называемой «вы- 
явление лиц и фактов, представляющих оперативный интерес» [2].

При анализе литературы обращает на себя внимание тот факт, что в теории оперативно-розыскной деятельности существует несколько подходов к определению направлений оперативного поиска, обобщив которые мы приходим к выводу, что мероприятия, направленные на выявление лиц и фактов, представляющих интерес для правоохранительных органов, целесообразно осуществлять: в местах концентрации лиц, представляющих оперативный интерес, и местах вероятного сбыта похищенного имущества; среди граждан, проживающих на обслуживаемой органами внутренних дел территории; в криминогенных группах; на обслуживаемых объектах (в отраслях); среди лиц, привлекавшийся к ответственности за совершение преступления [3].

Предложенная классификация содержит в себе общие направления оперативного поиска для всех оперативных подразделений органов внутренних дел и, безусловно, имеет немалое теоретическое и практическое значение. Однако в рамках рассматриваемого вопроса она требует большей конкретизации. Сказанное, в частности, вытекает из положений о том, что при изучении прикладных аспектов оперативно-служебной деятельности по борьбе с преступлениями экстремистской направленности конкретизация места или направления оперативного поиска позволяет оптимально использовать силы, средства и методы в целях получения первичной информации.

Несомненно, для выявления лиц, имеющих намерение совершить преступление экстремистской направленности и фактов их преступной деятельности, предложенные направления необходимо скорректировать.

Основными направлениями по выявлению признаков экстремистской деятельности являются:

постоянный мониторинг сети интернет, где могут функционировать информационные ресурсы экстремистской направленности

анализ оперативной обстановки;

установление признаков правонарушений, свидетельствующих о возможности совершения или совершенных правонарушений экстремистской направленности.

\section{Рассмотрим их подробнее.}

1. При проведении мониторинга интернет ресурсов необходимо учитывать, что в информационное про- странство наиболее активно используют экстремистские организации, которые можно условно разделить на группы:

а) сайты организаций с международными связями, осуществляющими деятельность на территории нескольких государств, которые пропагандируют идеи политического, экономического, экологического, религиозного экстремизма

б) сайты пропагандирующие экстремистские идеи на основе расовой и национальной принадлежности, деятельность которых направлена на разжигание межнациональной ненависти и вражды

в) сайты так называемого молодежного экстремизма, различного рода фанатские движения

г) сайты, напрямую не являющиеся экстремистскими, однако содержат информацию о том, как изготовить взрывчатые вещества, получить сильнодействующие ядовитые вещества, собрать самодельное взрывное устройство[4]

Проведение мониторинга сети Интернет позволяет получить большие объемы информации. Для определения причастности тех или иных лиц к экстремистской деятельности сотрудники органов внутренних дел проводят ряд оперативно-розыскных мероприятий.

2. Следующим направлением является анализ оперативной обстановки, по результатам которого, могут быть получены факты, свидетельствующие об экстремистских настроениях и намерениях:

- факты исполнения надписей, унижающих национальное достоинство, призывающих к насильственному свержению власти, а также содержащих фашистскую символику или ненормативную лексику, нанесенных на здания, сооружения и другие места;

- факты массовых драк, межнациональных конфликтов между лицами разных национальностей;

- повышение активности националистических групп;

- факты криминализации определенной части национальных диаспор;

- факты прибытия студентов на учебу из республик Северного Кавказа, многие из которых имеют родственников и иные связи из числа погибших в боевых действиях против Федеральных сил либо проходили обучение в исламских радикальных учебных заведениях на территории государств Ближнего Востока;

- вузы, в которых наблюдается наибольшая экстремистская активность молодежных и студенческих организаций, их сплоченность, а также принципы сплоченности (сформированы по национальному, земляческому признаку, выходцы 
из республик Северного Кавказа или иностранных государств);

- поддаются ли указанные студенты воспитательному воздействию руководства образовательных организаций, межнациональная напряженность и тенденции к обострению межэтнических отношений;

- воспринятые общественностью как несправедливые действия правоохранительных органов и суда по пресечению экстремистской деятельности, в связи с чем назревают конфликты на межэтнической почве;

- анализ оценки состояния обстановки на спортивных аренах при проведении футбольных матчей;

- факты хранения, наличия экстремистской символики (флаги, плакаты, транспаранты), в том числе при проведении публичных мероприятий;

- вербовка организаторами экстремистских группировок и ее участниками новых членов;

- выезд членов экстремистских организаций в другие регионы для участия в противоправных действиях;

- сведения о деятельности экстремистских сообществ, сформированных из числа иностранных граждан или лиц без гражданства, с указанием их характеристик;

- спонсорство и оказание помощи экстремистским, в т.ч. террористическим группировкам;

- организация выездов иностранных миссионеров, так называемые «дааваты» («призыв к исламу») по территории региона;

- квартиры, арендуемые в качестве «молельных домов» (место сбора), организация их контроля, в том числе из лиц иностранных государств;

- информации о связях молодежных групп экстремистской направленности с зарубежными организациями и др.
Это далеко не полный перечень фактов, свидетельствующих об экстремистских настроениях и намерениях, которые могут быть получены на основе анализа оперативной обстановки.

3. Следующим направлением в выявлении экстремистской деятельности это установление признаков правонарушений, свидетельствующих о возможности совершения или совершенных правонарушений экстремистской направленности;

К ним можно отнести:

- ношение соответствующей одежды

- использование символики, различные призывы и высказывания экстремистского толка

- издание и распространение экстремистской литературу

- осуществление поиска и вербовки новых членов

- действия, направленные на возбуждение ненависти либо вражды, а также на унижение достоинства человека либо группы лиц по признакам пола, расы, национальности, языка, происхождения, отношения к религии, а равно принадлежности к какой-либо социальной группе, совершенные публично или с использованием средств массовой информации.

Перечень указанных мероприятий является не исчерпывающим. Правоохранительные органы должны постоянно совершенствовать приемы и методы выявления признаков экстремистской деятельности, исходя из складывающейся оперативной обстановки. Организация работы в данном направлении позволит своевременно принимать меры превентивного характера, что в свою очередь позволить минимизировать негативные последствия от данного вида правонарушений.

\section{ЛИТЕРАТУРА}

1. 06 оперативно-розыскной деятельности: Федеральный закон от 12 августа 1995 г. № 144-Ф3: — [Электронный ресурс] // Информационно-справочная система «Консультант Плюс»

2. Теория оперативно-розыскной деятельности / Под ред. К. К. Горяинова, В.С. Овчинского, Г. К. Синилова. - 3-е изд., перераб. - М.: Норма: Инфра-М, 2010. - $368 \mathrm{c}$.

3. Алескеров В.И., Колокольчикова 0. Н., Федоткин А. И. Выявление и раскрытие преступлений экстремистской и террористической направленности, совершаемых с использованием сферы телекоммуникаций и компьютерной информации [Текст]: учеб.— практ. пособие.—- Домодедово: ВИПК МВД России, 2018. $-90 \mathrm{c}$.

4. Каримов В.Х. Актуальные вопросы противодействия терроризму и экстремизму. В сборнике: Проблемы формирования правового социального государства В современной России материалы XII всероссийской научно-практической конференции. Новосибирский государственный аграрный университет. 2016. C. 6-8.

с Антощенко Алексей Владимирович ( Kotova-vg@rambler.ru ). Журнал «Современная наука: актуальные проблемы теории и практики» 